\title{
Monitoring Vaccine Cold Chain Model with Coloured Petri Net
}

\author{
Fatima Ouzayd $^{1}$ \\ Smart Systems Laboratory, Rabat IT Center, \\ ENSIAS, University Mohamed V, \\ Rabat, Morocco
}

\author{
Hajar Mansouri $^{2}$ \\ Team EAS, LISER, \\ ENSEM, University Hassan II \\ Casablanca, Morocco
}

\author{
Manal Tamir ${ }^{3}$, Raddouane Chiheb ${ }^{4}$ \\ ADMIR, Rabat IT Center, \\ ENSIAS, University Mohamed V, \\ Rabat, Morocco
}

\author{
Zied Benhouma ${ }^{5}$ \\ CEREP Research Unit, \\ Higher School of Commerce \\ Sfax-Tunisia
}

\begin{abstract}
To protect and prevent vaccines from excessively high or low temperatures throughout the supply chain, from manufacturing to administration, it is necessary to monitor and evaluate vaccine cold chain performance in real time. Therefore, today, the need for smart tracking is a requirement that is accentuated with critical systems, such as the vaccine supply chain. In this article, we propose a model for instant cold chain monitoring using a colored Petri net (CPN). This model focuses on the central storage of vaccines and takes into account certain WHO (World Health Organization) recommendations. The simulation and the key performance indicators obtained can be useful for decision-makers in order to measure the effectiveness and efficiency of vaccine storage.
\end{abstract}

Keywords-Vaccine cold chain; monitoring; World Health Organization (WHO); colored Petri net $(\mathrm{CPN})$; performance

\section{INTRODUCTION}

Immunization programs have a major impact on the world's population by preventing many infectious diseases through vaccination [1]. The vaccine chain is made up of the activities and providers supplying, manufacturing, transport and administration of vaccines at the right time, to the right patient, of good quality [2]. Vaccines are biologically responsive products with their environment. In addition, any change in storage or transport conditions can have a negative impact on their usefulness and even cause undesirable effects [3]. The first parameter is the temperature at which the vaccines are exposed. This temperature should be monitored, recorded and reported throughout the supply chain, from its point of origin, the manufacturer, to its point of arrival, the place of vaccination. In order to prevent vaccines from their lifespan, they must be protected against exposure to too high or low temperatures throughout the supply chain, from manufacturing to administration. It is a shared responsibility between all actors in the chain. In our work, we will focus on the cold chain in the central store.

The aim is to provide a monitoring system to monitor the temperature of the hospital. This system detects and corrects technical issues in the cold chain components or other operational issues to maintain vaccine quality throughout the supply chain. The final goal is to make sure the cold chain is working properly according to the recommended standards and to avoid vaccination.

In this article, we propose a colored petri nets for the description of the storage process in a central warehouse. The model incorporates the verification of the transported vaccines, the dispatching of received vaccines according to their category as well as their storage in the refrigerator taking into consideration the maintenance function and the recommended storage time in the coolant-pack. We also proposed performance indicators based on a data set.

The remainder of this paper is organized as follows: in Section 2 we present the importance of vaccine supply chain in the immunization system. In Section 3, we identify the principles processes of vaccine supply chain based on the reference model SCOR. In Section 4, we propose our Coloured Petri Net model for storage and monitoring vaccine cold chain in central warehouse, Section 5 discusses our findings and, finally, Section 6 concludes the paper.

\section{IMMUNIZATION SYSTEM}

The vaccination or immunization plan is one of the best ways to save the lives of millions of children worldwide in both developed and developing countries. For [4], the Immunization is unquestionably one of the most cost-effective public health interventions available because that allows longterm decreasing in illnesses and disabilities, as well as reducing health spending, etc.

In order to improve its accessibility to children worldwide, the World Health Organization (WHO) launched the Expanded Program on Immunization (EPI) in 1974 with the objective to prevent seven of the most serious diseases [5]. Through, this objective, every year, GAVI buys vaccines for more than US\$ 1 billion. In 2015, several developing countries paid the additional co-financed vaccine (more than US\$ 130 million) [6].

For this purpose, all stakeholders, WHO, UNICEF, Bill \& Melinda Gates Foundation and GAVI, has given more 
attention to the different constraints that condition the flow of vaccine throughout the immunization system and particularly the supply chain. Today, the improvement of the supply chain is one way to ensure that all vaccines stay safe and effective, and reach the children who need them. This requires a system to achieve the six rights of supply-chain management [2]: 6 Rights (product, quantity, condition, place, cost and temperature).

For 2020 horizon, GATES Foundations with other stakeholders set as objective to prevent more than 11 million deaths, 3.9 million disabilities, and 264 million illnesses [7]. However, all vaccines strategies continue to face delivery challenges in terms of supply chain. Unfortunately, gaps in vaccine cold chain and logistics (CCL) systems are one of the common factors limiting full and equitable access to the benefits of immunization. This is because such gaps undermine the availability and potency of vaccines at the point of administration, prevents the introduction of new life-saving vaccines, and waste precious human and financial resources [8]. The vaccines cold chain can't be efficient without four elements (a) pertinence estimation of needs system, (b) secure delivery vaccines system, (c) optimization cost and delay and (b) performance cold chain network (sustainably closing the immunization coverage gap, introducing new vaccines and securing sustainable funding) [9]. In the following, we will focus on the details of the vaccine supply chain.

\section{VACCINE SUPPLy CHAIN}

In this section, we first extend the processes of vaccine supply chain, and then we propose the level 2 of SCOR model that describes the processes and sub-processes of vaccine supply chain.

According to WHO [10], the vaccine supply chain contains the following processes: estimating of needs, storage, distribution, monitoring and supervision.

\section{A. Processes of Vaccine Supply Chain}

\section{1) Estimating of Needs}

The aim of this process is to ensure an adequate supply of vaccines, diluents and safe-injection equipment by assuring quality to every immunization service. Indeed, the effective management and storage of supplies must optimize costs, prevent high wastage rates and stock-outs, and improve the safety of immunizations. There are two methods that are commonly used to estimate vaccine and safe-injection equipment needs at the provincial level:

- Estimating vaccine and injection equipment needs based on the target population.

- Estimating vaccine and injection equipment needs based on previous consumption.

\section{2) Storage}

This process is about how to select and maintain cold-chain equipment, how to estimate the total volume of vaccines and safe- injection equipment to be stored and how to manage the storage of these items. About vaccines storage condition, WHO proposes that each vaccine has its own specific storage requirements, so it is extremely important to know how long and at what temperature each vaccine can be stored. Also, for selecting appropriate cold chain equipment, WHO recommends to have information about reliable electricity and local situation. Therefore, there is another activity in this process. It's about storage capacity. That concerns fixing the total volume available to store vaccines.

\section{3) Distribution}

The aim of distribution systems for vaccines and safeinjection equipment is "to ensure continuous availability of adequate quantities of potent vaccine and safe-injection equipment" [10]. Otherwise, the distribution systems must allow having a well-functioning distribution system and clearly establishing: the supply period for each level and the corresponding quantities of vaccines and safe-injection equipment to be supplied, and the suitable route and transport needed to distribute the vaccines and safe- injection equipment.

\section{4) Monitoring and Supervision}

According to [8], in order to conserve its potency and safety, each vaccine must be strictly maintained within a specific temperature range from the manufacturer to the recipient.

In Table I, we present an example of temperatures of vaccines in central Warehouse or regional Warehouse according to [11].

TABLE I. STORAGE TEMPERATURES OF VACCINE IN CENTRAL WAREHOUSE AND REGIONAL WAREHOUSE

\begin{tabular}{|l|l|l|}
\hline Vaccine & Central Warehouse & Regional Warehouse \\
\hline DTC & $+2^{\circ} \mathrm{C}$ à $+8^{\circ} \mathrm{C}$ & $+2^{\circ} \mathrm{C}$ à $+8^{\circ} \mathrm{C}$ \\
\hline HB & $+2^{\circ} \mathrm{C}$ à $+8^{\circ} \mathrm{C}$ & $+2^{\circ} \mathrm{C}$ à $+8^{\circ} \mathrm{C}$ \\
\hline BCG & $+2^{\circ} \mathrm{C}$ à $+8^{\circ} \mathrm{C}$ & $+2^{\circ} \mathrm{C}$ à $+8^{\circ} \mathrm{C}$ \\
\hline VAT & $+2^{\circ} \mathrm{C}$ à $+8^{\circ} \mathrm{C}$ & $+2^{\circ} \mathrm{C}$ à $+8^{\circ} \mathrm{C}$ \\
\hline Hib & $+2^{\circ} \mathrm{C}$ à $+8^{\circ} \mathrm{C}$ & $+2^{\circ} \mathrm{C}$ à $+8^{\circ} \mathrm{C}$ \\
\hline VPO & $-15^{\circ} \mathrm{C}$ à $-25^{\circ} \mathrm{C}$ & $-15^{\circ} \mathrm{C}$ à $-25^{\circ} \mathrm{C}$ \\
\hline VAR & $-15^{\circ} \mathrm{C}$ à $-25^{\circ} \mathrm{C}$ & $-15^{\circ} \mathrm{C}$ à $-25^{\circ} \mathrm{C}$ \\
\hline RR & $-15^{\circ} \mathrm{C}$ à $-25^{\circ} \mathrm{C}$ & $-15^{\circ} \mathrm{C}$ à $-25^{\circ} \mathrm{C}$ \\
\hline
\end{tabular}

Indeed, the activity of monitoring and supervision takes place monthly. The aims of monitoring vaccines and safeinjection equipment are:

- Ensuring the availability of adequate quantities and the required quality of each item;

- Ensuring appropriate use in service delivery;

- Enabling the timely detection of management problems in the implementation of immunization activities so that corrective action can be taken;

- Guiding the planning process. 


\section{SCOR MODEl OF VACCINE SUPPly CHAIN}

\section{A. Modelling Techniques of Vaccine Supply Chain}

The literature represents various modelling techniques among which we quote: UML, Petri Networks, BPMN, SCOR, ABM, ARIS, mathematical programming ...

For the vaccine supply chain, many authors have used modelling methods to measure the performance of the different links of this chain. For example, [12] reviews the literature on model-based supply chain network design to identify the applicability of these models for the design of a vaccine supply chain. Author in [13] has opted for the mathematical programming to model the vaccine distribution network.

\section{B. SCOR Model of Vaccine Supply Chain}

The Supply Chain Operations Reference (SCOR) model was proposed by the Supply Chain Council in 1996. The SCOR model present an approach, processes, indicators and the best practices for evaluate and diagnose the Supply Chain. This methodology based on the client is generic, rigorous, complete and structuring [14]. The SCOR model focuses on the supply chain management function from an operational process perspective and includes customer interactions, physical transactions, and market interactions [15].

The main global processes of SCOR are: Plan, Source, Make, Deliver, and Return. For Level 2, SCOR recommend to describe core processes according the production strategy. There is the "Make-to-stock" category, the "Make-to-order" category and the "Engineer-to-order" category. Level 3 of the SCOR model specifies the best practices of each process.

In Fig. 1, we define the level 2 of SCOR model of Moroccan vaccine supply chain [11]. The upstream chain concerns the producers who supply the needs of the Moroccan partners. The central or regional warehouse replenishes the hospitals according to the national immunization plan (M1 bloc: manufacturing for storage, S1 bloc: Supply for storage, D1: Deliver for storage and DR1: Return for .......).

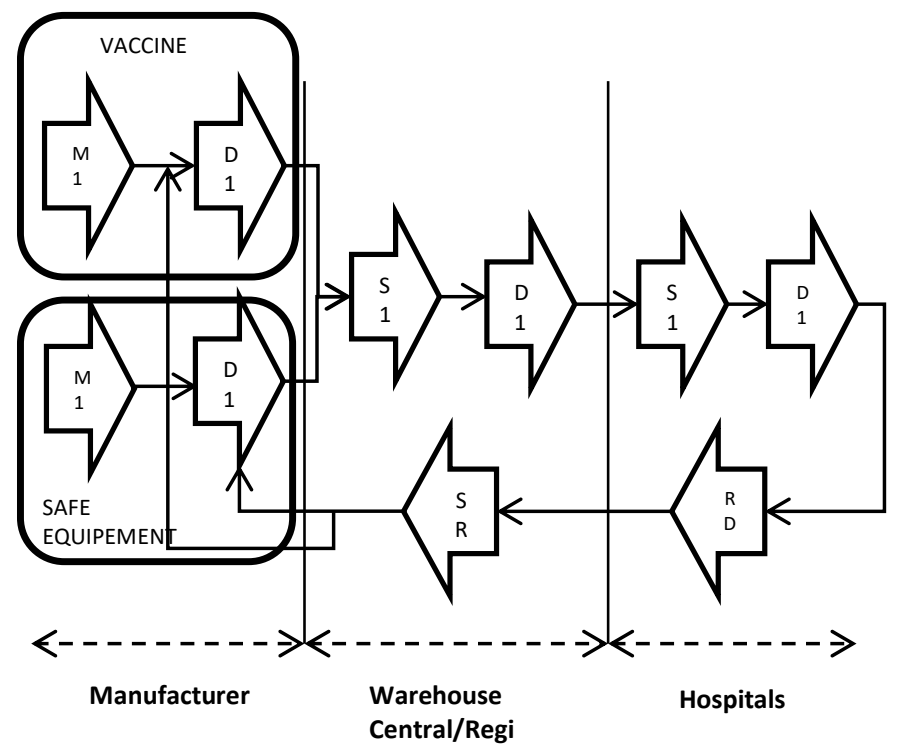

Fig. 1. SCOR Model of vaccine supply chain.
The objective of the SCOR model is to present an overview which describes the global operation of the chain in terms of: partners, global processes, critical processes which include the cold chain process. In fact, this modelling will facilitate the study of the performance of the vaccine chain through that of the cold chain.

\section{PERFormance OF VACCINE SupPly Chain By CONTROLLING THE COLD CHAIN}

The achievement of the goals set out in the vaccination requires a supply chain and logistics from end to end functional. Indeed, the supply chain is constrained effectively manage the increase in the introduction of new vaccines, from adapt to the needs of new delivery or delivery strategies take advantage of new technological advances in the field of cold chain equipment to improve their efficiency. This requires the establishment of a system to obtain the six supply chain management criteria: the right product, right amount, right condition, right place, right time and the right cost. The evidence indicates problems in seven areas: limitations in supply chain system design, insufficient human resources, Inefficient use of data for management, weak distribution systems, inadequate budgeting and distribution systems and deficient cold chain equipment [2].

In this sense, GAVI [16] has proposed a supply chain strategy based on 5 axes: (1) Supply chain leadership, (2) Continuous improvement \& planning, (3) supply chain data for management, (4) supply chain system design and cold chain equipment. For that, we propose monitoring model that allow evaluating complaint vaccine with Coloured Petri Net. The objective of the model is to automate tracking of storage and conservation vaccine in global warehouse.

\section{A. Tracking Model of Storage Vaccine Cold Chain}

\section{1) Coloured Petri Net and CPN Tools}

Coloured Petri Net offers a modelling framework that is perfectly for distributed and concurrent processes with both synchronous and asynchronous communication [17].

In addition, they are useful in modelling both nondeterministic and stochastic processes as well. We introduce for brief presentation of Coloured Petri Net theory, developed by [18]. CPN is a tuple $(\Sigma, \mathrm{P}, \mathrm{T}, \mathrm{A}, \mathrm{N}, \mathrm{C}, \mathrm{G}, \mathrm{E}, \mathrm{I})$ satisfying the following requirements:

a) $\Sigma$ is a finite set of non-empty types, also called colour sets.

b) $\mathrm{P}$ is a finite set of places.

c) $\mathrm{T}$ is a finite set of transitions.

d) $\mathrm{A}$ is a finite set of arcs such that: $\mathrm{P} \cap \mathrm{T}=\mathrm{P} \cap \mathrm{A}=\mathrm{T}$ $\cap \mathrm{A}=\varnothing$.

$\mathrm{T} \times \mathrm{P}$.

e) $\mathrm{N}$ is a node function. It is defined from $\mathrm{A}$ into $\mathrm{P} \times \mathrm{T} \cup$

f) $\mathrm{C}$ is a color function. It is defined from $\mathrm{P}$ into $\Sigma$.

$g$ ) $\mathrm{G}$ is a guard function. It is defined from $\mathrm{T}$ into expressions such that: $\forall \mathrm{t} \in \mathrm{T}$ : [Type $(\mathrm{G}(\mathrm{t}))=\mathrm{B} \wedge$ Type $(\operatorname{Var}(\mathrm{G}(\mathrm{t}))) \subseteq \mathrm{S}]$. 
h) $\mathrm{E}$ is an arc expression function. It is defined from $\mathrm{A}$ into expressions such that: $\forall \mathrm{a} \in \mathrm{A}$ : $[$ Type $(\mathrm{E}(\mathrm{a}))=\mathrm{C}(\mathrm{p}) \mathrm{MS} \wedge$ $\operatorname{Type}(\operatorname{Var}(E(a))) \subseteq S]$ where $p$ is the place of $N(a)$.

i) $\mathrm{I}$ is an initialization function. It is defined from $\mathrm{P}$ into closed expressions such that: $\forall \mathrm{p} \in \mathrm{P}$ : [Type $(\mathrm{I}(\mathrm{p}))=\mathrm{C}(\mathrm{p}) \mathrm{MS}]$.

$\mathrm{CPN}$ is tool and framework that allow design, specification, validation, and verification of systems [19].

\section{B. Storage and Monitoring Coloured Petri Net of Vaccine Cold Chain}

\section{1) Description of the system}

In this work, we focus on the storage process in a central warehouse. We present an example of this system with the following elements: Two operators, two refrigerators, thermometers, etc.

The extract of declaration system with CPN Tools is shown below in Fig. 2:

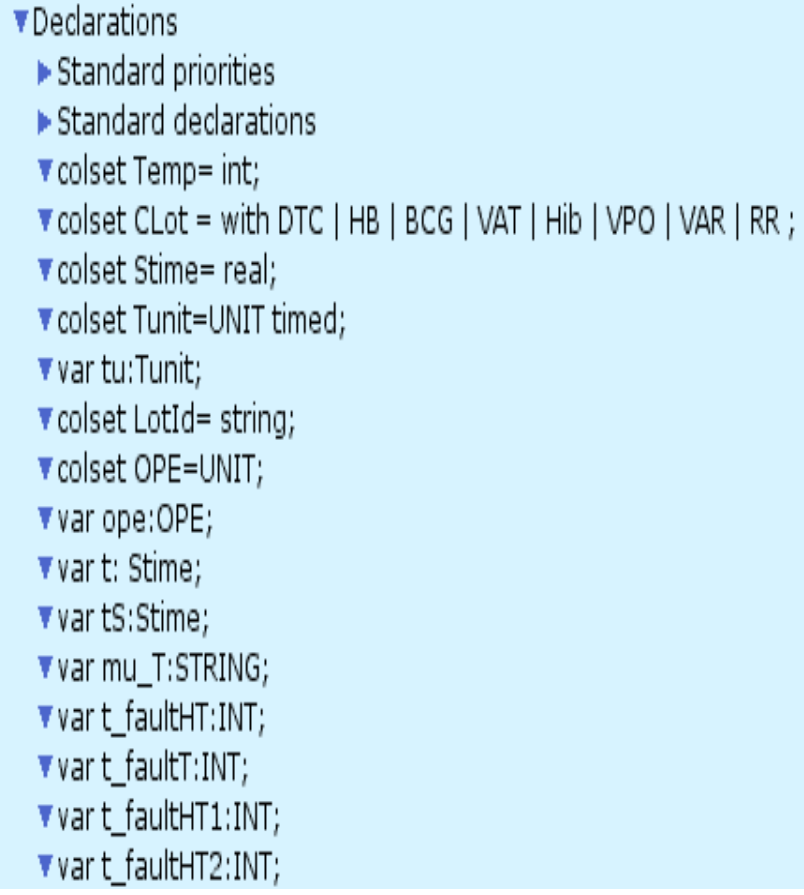

Fig. 2. Extracts of declaration system with CPN tools.

The used colors are illustrated in Table II; different variables were defined for the system. Some of these variables are used for the monitor and performance analysis and some are used for the model behavior verification. The process of vaccine storage is illustrated in Fig. 3, 4 and 5.

The token of BatchContent place represents ID of the batch, arrival time of the batch which is taken randomly from the exponential distribution and finally the content of the batch. The variable a is involved to take on the random token, from the place Temp to the transition Reception. The output of the transition is a timed token, with four different values. The reception control transition is responsible for the separation of the batches in two groups. Place Set 1 contains only batches containing type 1 vaccines whereas place set 2 contains batches containing type 2 vaccines. The control of the temperature of the vaccines contained in each lot, allow the reject of any vaccine whose temperature does not correspond to the norm. The compliant vaccines will be stored in the refrigerator. Due to different temperature standards for vaccines 1 and 2 we distinguish two types of refrigerator. In case the refrigerator thermometer is out of order the vaccines will be transferred to the coolant-pack. Therefore, we identify an example of place with closet and type.

TABLE II. NAME AND TYPE OF COLSET

\begin{tabular}{|l|l|l|}
\hline Place Name & Colset & Type \\
\hline Vaccine Name & Colset & Enumerated \\
\hline BatchName & Colset & Enumerated \\
\hline BatchContent & ClotVaccin & Product timed \\
\hline Operator & OPE & UNIT \\
\hline Set 1 & ColsetVaccin2 & Product timed \\
\hline Set 2 & ColsetVaccin2 & Product timed \\
\hline Campliant Set1 & ColsetVaccin2 & Product timed \\
\hline Campliant Set2 & ColsetVaccin2 & Product timed \\
\hline NoComplaint2 & ColsetVaccin2 & Product timed \\
\hline Refrigerator 1 & ColsetVaccin2 & Product timed \\
\hline Refrigerator 2 & ColsetVaccin2 & Product timed \\
\hline Reorder & ColsetVaccin2 & Product timed \\
\hline Thermometer good & Unit & \\
\hline Thermometer broken & Unit & \\
\hline Cool-Packs1 & ColsetVaccin2 & Product timed \\
\hline Cool-Packs2 & ColsetVaccin2 & Product timed \\
\hline
\end{tabular}

The output of the transition is a timed token, with four different values. The receive control transition is responsible for separating batches into two groups. Set 1 contains only batches containing type 1 vaccines (temperature $+2^{\circ} \mathrm{C}$ à $+8^{\circ} \mathrm{C}$ ), while set 2 contains batches containing type 2 vaccines (temperature $-15^{\circ} \mathrm{C}$ à $-25^{\circ} \mathrm{C}$ ) (see Table III). The temperature control of the vaccines contained in each batch allows the rejection of any vaccine.

TABLE III. STANDARD TEMPERATURES OF 2 SETS VACCINES

\begin{tabular}{|l|l|l|}
\hline Vaccine & Standard Temperature & Set \\
\hline $\begin{array}{l}\text { DTC-HB-BCG-VAT- } \\
\text { HiB }\end{array}$ & $+2^{\circ} \mathrm{C}$ à $+8^{\circ} \mathrm{C}$ & SET1 \\
\hline VPO-VAR-RR & $-15^{\circ} \mathrm{C}$ à $-25^{\circ} \mathrm{C}$ & SET2 \\
\hline
\end{tabular}

In this model, we have 2 levels of monitoring. The first is controlling the batches after reception. This control, we allow identifying the number of the non-complaint vaccine through transportation (PLACE NO-COMPLAINT2). The second is monitoring the respect of temperature under warehouse from storage (validation, verifications and conservation) to replenishment of the regional warehouses. If the products correspond to the recommended temperatures then they are stored in refrigerators or they are rejected and classified as noncompliant vaccines (PLACE NOCOMPLAINT). We add also, in this place the case of the refrigerator (with thermometer) does not work then the new vaccine that arrives must be kept in the coolant-pack while waiting to correct the failure. 


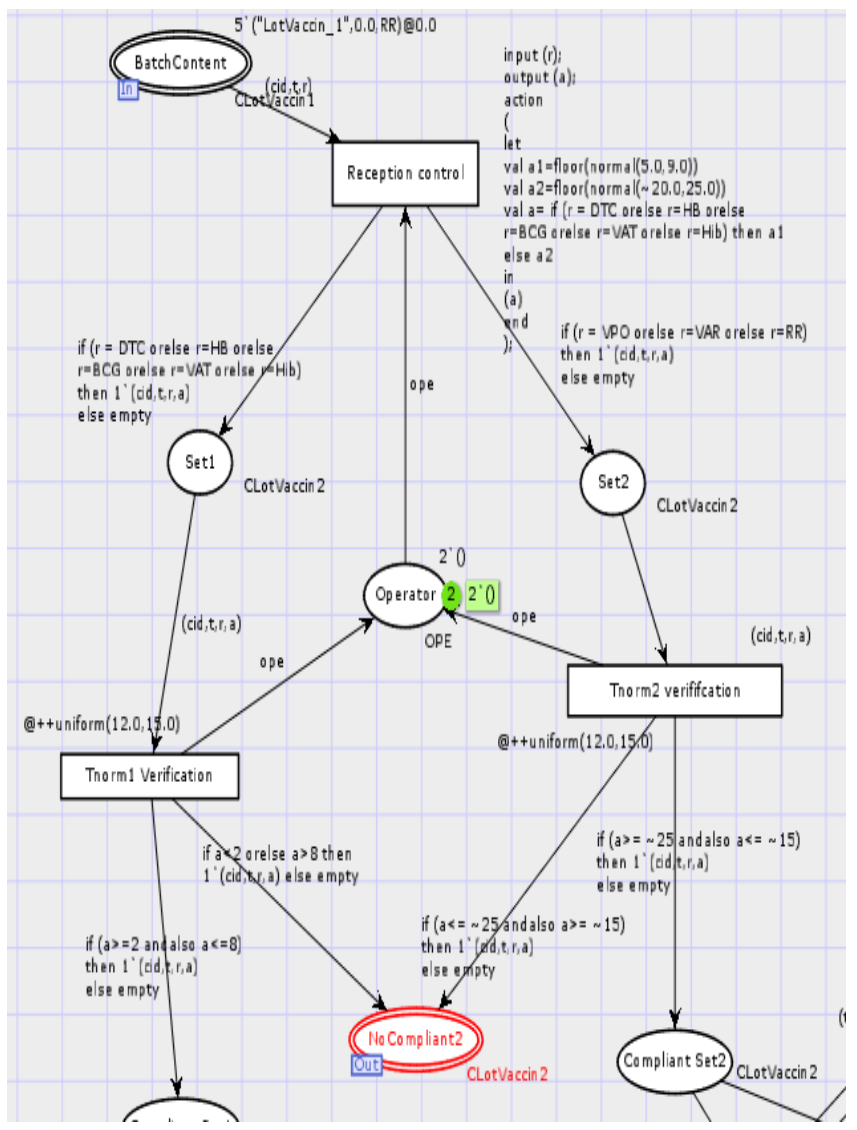

Fig. 3. Reception and control of temperature vaccine.

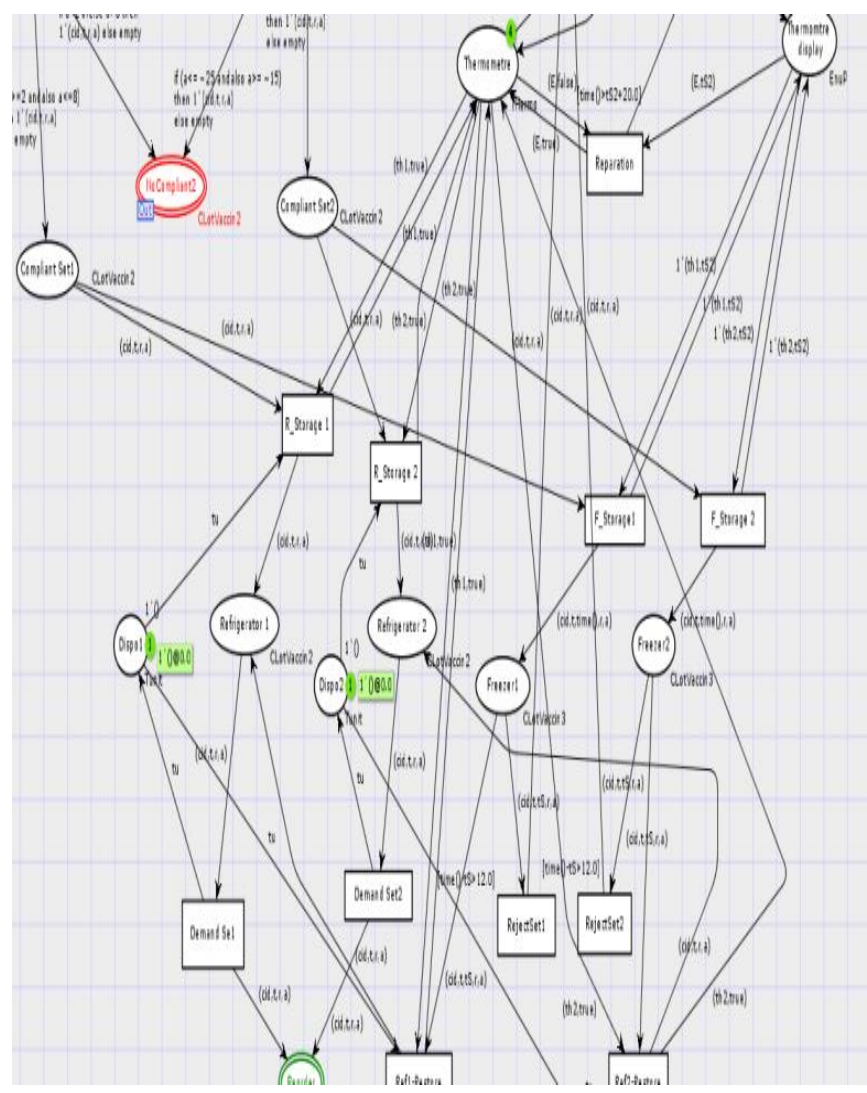

Fig. 4. Dispatching of vaccine in the refrigerators.

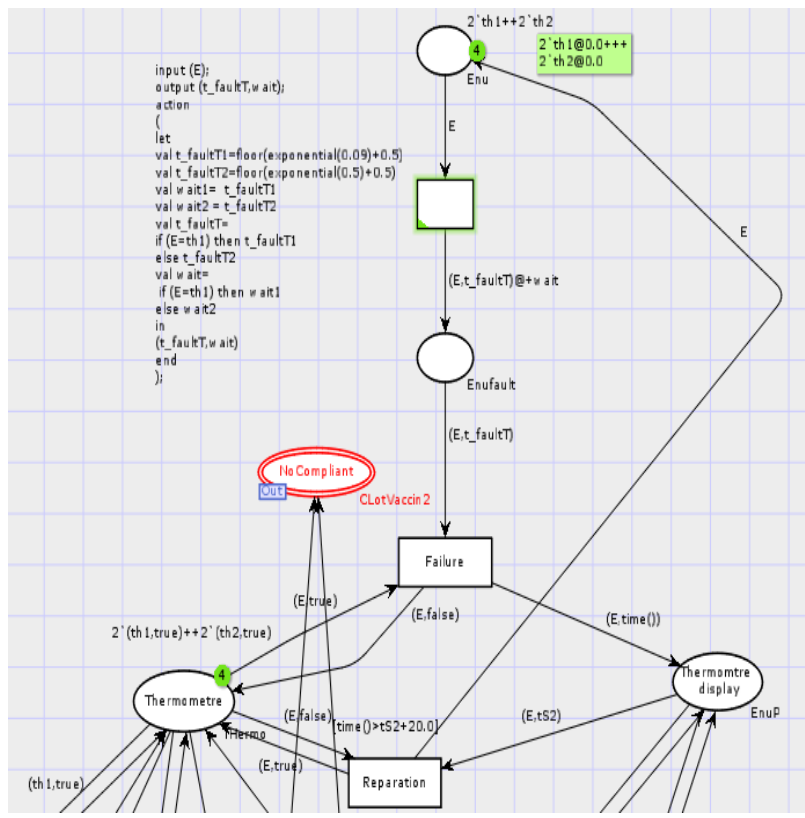

Fig. 5. Maintenance system of the refrigerators.

\section{2) Simulation and Validation the Model}

According to [20] there is a critical Cold Chain Logistics (CCL)-related issues such as delayed new vaccine introductions due to insufficient cold chain capacity, vaccine potency compromised by exposure to dangerous temperatures, and missed immunization opportunities from stock-outs. To better target such gaps and carry out corrective actions, National Immunization Programs (NIPs) need to assess CCL systems on their performance, adopting key performance indicators (KPIs) that evaluate each core CCL system task against NIP needs. Our work focuses on the performance evaluation of vaccine storage in warehouse. The aim objective of central warehouse is to:

- Reduce the risks of the break in the cold chain

- Monitor temperatures in real time

- Manage changes in product availability, inventory movements and delivery (number of insulated bags, ...)

The model that we propose allows evaluating several scenarios. We focused at first time to measure five indicators.

The first KPI represent the non-compliant vaccines due to the non-respect of the cold chain during transport. Indeed, as mentioned above, before storing vaccines in the warehouse, a temperature check is necessary. Non-conforming vaccines are rejected by stopping the process.

The "flowtime_Vaccins_Non_Compliant2" indicator represent the residence time of this type of non-compliant vaccines in the process.

The third KPI is the rate of the non-compliance vaccine due to refrigerator failures. As shown in Fig. 6, the vaccine service rate varies according to the failure rate of the refrigerator. For the failure rate between $0.1 /$ hour for th 1 and $0.9 / \mathrm{h}$ we get a service rate of $88 \%$ while for the failure rate between $0.001 /$ hour for th 1 and $0.009 / \mathrm{h}$ for th 2 we get a service rate of 
99\%. This also has an impact on the residence time of this type of non-compliant vaccines in the process. Indeed, when the refrigerator's thermometer does not work, any new vaccine introduced into the warehouse will be stored in the coolantpack until the thermometer is repaired. The last indicator represents the flow time of the compliant vaccines in the process.

For simplicity, we considered that the replenishment management rules are automatic.

Note that these statistics have been calculated for data that is not necessarily independent or identically distributed.

\begin{tabular}{|c|c|c|c|c|c|}
\hline \multicolumn{6}{|c|}{ Untimed statistics } \\
\hline Name & Count & Sum & Avrg & Min & Max \\
\hline Percentage_transport_Non_Compliant & 7210 & 1234 & 0.171151 & 0 & 1 \\
\hline flowtime_Vaccins_Non_compliant & 2 & 54.415273 & 27.207637 & 25.577353 & 28.837920 \\
\hline flowtime_Vaccins_Non_compliant_2 & 1234 & 16663.172985 & 13.503382 & 12.000829 & 14.997730 \\
\hline flowtime_Vaccins_compliant & 5976 & 81103.204572 & 13.571487 & 12.000006 & 36.290227 \\
\hline percentage_serviced & 5978 & 5976 & 0.999665 & 0 & 1 \\
\hline
\end{tabular}

Simulation steps executed: 76201

Model time: 843284.68658

Note that these statistics have been calculated for data that is not necessarily independent or identically distributed.

\begin{tabular}{|c|c|c|c|c|c|}
\hline \multicolumn{6}{|c|}{ Untimed statistics } \\
\hline Name & Count & Sum & Avrg & Min & Max \\
\hline Percentage_transport_Non_Compliant & 6452 & 1300 & 0.201488 & 0 & 1 \\
\hline flowtime_Vaccins_Non_compliant & 693 & 19806.173226 & 28.580337 & 24.243625 & 45.372550 \\
\hline flowtime_Vaccins_Non_compliant_2 & 1300 & 17594.364584 & 13.534127 & 12.004182 & 14.998509 \\
\hline flowtime_Vaccins_compliant & 5152 & 90664.141949 & 17.597854 & 12.000236 & 39.844453 \\
\hline percentage_serviced & 5845 & 5152 & 0.881437 & 0 & 1 \\
\hline
\end{tabular}

Simulation steps executed: 66410

Model time: 14508.3540798

Generated: Mon Mar 26 13:48:52 2018

Fig. 6. Results of rate service with 2 scenarios of failure.

\section{CONCLUSION}

In this paper, we presented monitoring temperature model in vaccine cold chain with Coloured Petri Net. This automation model allows to supervising this physical parameter and to evaluate the performance cold chain in real time.

The decision maker can simulate the several scenarios to measure efficiency of system and propose some solutions. These models allow evaluating a performance of system, by fixed a means indicators: ComplaintVaccine, NoComplaintVaccine, utilization resource, Rate serveries satisfaction, etc.

We have integrated the maintenance function for evaluate the impact of reactive reparation on complaint vaccine. Indeed, we can adapt this model to any storage vaccine system in central warehouse because this model is generic monitoring temperature system with $\mathrm{WHO}$ recommendations.

In the next steps, we will propose a global architecture based on multi-agent systems for the implementation of the monitoring temperature model in vaccine cold chain with Coloured Petri Net.
We will also extend this model to include other global processes: supply, production, cold chain and distribution to ensure analysis and control of global vaccine chain performance.

\section{REFERENCES}

[1] Lloyd.JS, "Improving the cold chain for vaccines," WHO Chronicle 1977 Jan;31 (1):13-8.

[2] L. Evertje Duijzer, W.Van Jaarsveld,R.Dekker, "Litterature review: The vaccine supply chain" European Journal of Operational Research 268 (2018) 174-192

[3] J.Lloyd, J.Cheyne "The origins of the vaccine cold chain and a glimpse of the future" Vaccine 35 (2017) 2115-2120

[4] Houari, M., (2017) Vaccins : Actualités et exigences en Contrôle qualité, Medecine Thesis, Mohammed V University, Morocco.

[5] Ehreth J (2003) 'The global value of vaccination', Vaccine, Vol. 21, pp.596-600.

[6] Ateudjieu, J., Kenfack, B., Nkontchou, B. W., \& Demanou, M. (2013), 'Program on immunization and cold chain monitoring: The status in eight health districts in Cameroon', BMC Research Notes, Vol.6, $\mathrm{N}^{\circ}$, pp.1,

[7] Noni E. MacDonald and all, "Moving forward on strenghening and sustaining National Immunization Technical Advisory Groups (NITAGs) globally: Recommendations from the $2^{\text {nd }}$ global NITAG network meeting," Vaccine 35 (2017) 6925-6930

[8] Ashok, A., Brison, M., \& LeTallec, Y. (2017), 'Improving cold chain systems: Challenges and solutions', Vaccine, Vol. 35, N¹7, pp.22172223.

[9] Humphreys G. (2011), Vaccination: rattling the supply chain. Bull World Health Organ, Vol. 89, N5, pp.324-325.

[10] Judith R.Kaufmann and all, "Vaccine supply chains need to be better funded and strenthened, or lives will be at risk" health affairs 30 , no. 6 (2011): 1113-1121

[11] Cohen, R. (2018) Guide Marocain Vaccinologie, [online], Université Cadi Ayyad, 2ème Edition, https://pharmacie.ma/uploads/pdfs/guide_marocain_de_vaccinologie.pdf (Accessed 21 March 2018).

[12] Lemmens S., Decouttere C., Vandaele N., Bernuzzi M. (2016), “A review of integrated supply chain network design models: Key issues for vaccine supply chains", Chemical Engineering Research and Design, 109 ( 2016 ) 366-384

[13] Sheng-I Chen, (2012), "Modeling the WHO-EPI vaccine supply chain in low and middle income countries", thesis, University of Pittsburgh, 2012.

[14] John Paul, Jean-Jacques Laville, SUPPLY CHAIN MAGAZINE, VOL 13, pp.96 MARS 2007

[15] Christiansen, B., (2015) 'Handbook of Research on Global Supply Chain Management', PryMarke, LLC, USA, pp.49

[16] S.Ozawa and all, "Funding gap for immunization across 94 low and middle-income countires, "Vaccine 34 (2016) 6408-6416

[17] Jensen, K. (1994), 'An Introduction to the Theoretical Aspects of Coloured Petri Nets', Computer Science, Vol. 803, Springer-Verlag, pp. 230-272.

[18] Kristensen, L. M., Christensen S., Jensen. K. (1998), 'The practitioner's guide to coloured Petri nets', International Journal on Software Tools for Technology Transfer, Vol.2, pp.98-132.

[19] Kurt J., Kristensen L.M., Wells L. (2007), "Coloured Petri Nets and CPN Tools for modelling and validation of concurrent systems", Int J Softw Tools Technol Transfer, Springer-Verlag, Vol. 9, Issue 3-4, pp 214.

[20] Brison, M. and LeTallec Y., (2017), 'Transforming cold chain performance and management in lower-income countries', Vaccine, Vol.35, pp.2107-2109, 